\title{
DIE EKUMENIESE ROEPING VAN DIE KERK
}

\author{
Prof. P. J. Coetzee
}

OP die jongsgehoue kongres van die Dogmatologiese Werkgemeenskap (1973) is die wens uitgespreek ,dat ons aktueel en konkreet in ons studie moet wees". In hierdie voordrag vind $u$ 'n poging om hieraan enigsins gevolg te gee.

I. Inleidend: Enkele opmerkings oor die begrippe kerk en ekumene.

II. Riglyne uit die Heilige Skrif.

III. Daar moet onderskei word tussen geskeidenheid en verskeiden. heid.

A. Geskeidenheid.

B. Verskeidenheid.

\section{Inleidend: Enkele opmerkings oor die begrippe kerk en ekumene}

Dit is wesenlik van die kerk dat dit van die Here is. In die $\mathrm{Ou}$ Testament blyk dit uit die begrippe eda Jahveh en kahal Jahveh en in die Nuwe Testament uit begrippe soos ekklésia en kuriaké. Wat Israel in die Ou Testament meer as net nog 'n volk onder die volke maak, is die feit dat dit in 'n besondere sin volk van God is. In die Nuwe Testament word dit van die kerk nog uitdrukliker gesê. Vergelyk bv. Matth. $16: 18:$,... op hierdie rots sal Ek my gemeente bou ..."; Rom. 14: 8: "... of ons dan lewe en of ons sterwe, ons behoort aan die Here"; 1 Kor. 1 : 2: "aan die gemeente van God wat in Korinte is, aan die geheiligdes in Christus Jesus, die geroepe heiliges, saam met almal wat die Naam van onse Here Jesus Christus in elke plek aanroep, hulle sowel as onse Here". Die beelde vir die kerk in die Heilige Skrif benadruk ook hierdie verbondenheid, bv. die liggaam van Christus en die tempel van die Heilige Gees. Die H. Kateg., Sondag 21, vr. en antwoord 54 neem sy uitgangspunt in wat die Seun van God doen; art. 27 N.G.B. beklemtoon die verbondenheid met Christus en die Heilige Gees. (Vgl. 0.a. ook die Apol. Conf. Aug., Art. 7 en 8). Christus is die Hoof van die kerk. Die hele kerkregering moet in die lig van sy heerskappy benader word.

Die grond vir die eenheid van die kerk is ten diepste die feit dat die Here van die kerk én is in wese en in handele. In die gemeenskap met God rus die gemeenskap met mekaar. 1 Joh. $1: 6,7$ : „As ons sê dat ons met Hom gemeenskap het en in die duisternis wandel, dan lieg ons en doen die waarheid nie. Maar as ons in die lig wandel soos $\mathrm{Hy}$ in die lig is, dan het ons gemeenskap met mekaar..." Die Ou Testament laat blyk dat die eenheid van Israel verlore gaan as die band met God vir 'n koalisie met 'n veelheid van gode verruil word (vgl. o.a. 1 Kon. $11: 1-13$ ). Die nadruk val die sterkste op die eenheid en enigheid van God waar die versameling van die verstrooide kinders van Israel die duidelikste belowe word. (Vgl. o.a. Jes. 43 : 5 e.v.). Die eenheid van die heilshandele van God is ook duidelik by die oorgang van die universele (Adam, Noag) na die partikuliere (Abraham, Israel); ten slotte val die volle 
lig op die kneg van die Here (in die profesie van Jesaja), om juis hiervandaan uit sy wydste perspektief te ontvou. In die Nuwe Testament is die wesensband tussen die eenheid van God en die eenheid van sy kerk uit alle geslagte en oor die hele wêreld duidelik uit Joh. 17 (vs. 11: ,... sodat hulle een kan wees net soos Ons"), en Efes. 4 : 1-16 (die herhaalde akkoorde: „een”). Een sterf vir vele, en daardeur word die vele een (bv. Joh. $11: 48-52$; Joh. $10: 15$, 16; 1 Kor. 1 : 10 e.v.). Dit word ook weerspieël in die tekens en seëls van die Nuwe Verbond (Gal. 3 : 27, 28; 1 Kor. 10 : 16, 17; 1 Kor. $12: 13 ; 1$ Kor. $11: 18$ e.v.). Alle dinge word onder één Hoof saamgevat (Efes. 1 : 10, 22, 23). Uit die H. Kateg. Sondag 21; N.G.B., art. 27; Dordtse Leerreëls I, 7 en 8 blyk dat een en dieselfde uitverkiesing vir al God se kinders geld. Dit is dieselfde Heilige Gees en dieselfde Heilige Skrif. Johannes sien sewe goue kandelaars (dit is die kerk in sy geheel) en tussen die sewe kandelaars in Een soos die Seun van die mens (Openb. $1: 12,13$ ). Hy regeer sy kerk deur sy Woord en Gees.

Die kerk van Christus is nie 'n vergadering van individuele gelowiges sonder meer nie. Die kerk met sy universele karakter en sy ekumeniese roeping is die samebinding van nasies in hulle gelowiges (Efes. 2 : 16; vgl. o.a. Matt. 28 : 19; Openb. 7 : 4 e.v.; 7 : 9 e.v.; $21: 24,26)$. Die Evangelie plaas die kerk in die dimensie van die ekumeniese: die hele mensheid (Kol. 1 : 23; Matt. 24 : 14; Mark. 16 : 15; Openb. $14: 6$ ); elke mens (Kol. $1: 28$ ); elke nasie (Matt. $28: 19$; Openb. $10: 11$ ) is daarby betrokke. Die Evangelie moet aan alle nasies tot ' $n$ getuienis gebring word (Matt. $24: 14$ ). Terwyl die kerk onder die ou bedeling in meerdere mate nasionaal begrens was, word die kerk onder die nuwe bedeling uit alle volke vergader en is dit bestem om as ecclesia universalis oor die hele wêreld uit te brei (Matt. $8: 11 ; 28: 19$; Rom. $10: 10-12$; Efes. 2 : 14; Openb. 7 : 9; Art. 27 N.G.B.). Die Heilige Gees bind die kerk in sy geheel saam tot ' $n$ eenheid. Die aanwesigheid van die Heilige Gees kom tot openbaring in ampte en gawes waarvan die apostoliese die grondslag vorm (1 Kor. $12: 4,7-11,28-31$; Efes. 4 : 11).

Ons maak vervolgens ' $n$ par aantekeninge oor die begrip ekumene:

Die uitdrukking kat' holén tén oikoumenén dui op verbreidheid, uitgestrektheid oor die hele wêreld. Oikoumené beteken die bewoonde, die woonplek. In die LXX kom die woord voor in die sin van "wêreld", ,aarde" of "land". In die Hellenisme het dit die betekenis van „,bewoonde aarde" of „,beskaafde wêreld" (dit het dan veral op die Romeinse imperium gesien). In die Nuwe Testament kom dit vyftien keer voor. Dit word vertaal as "die hele wêreld" (Hand. $17: 31$; Matt. $24: 14$ ) of in die sin van die politieke en beskaafde wêreld van die Romeinse Ryk (Luk. 2 : 1; Hand. $17: 6$ ). In Hebr. $2: 5,8:$ "die toekomstige wêreld".

In die tweede eeu is dit reeds op die kerk van toepassing. Policarpus spreek van "die katolieke kerk in die hele oikoumené". Dit het dus alles te maak met die geografiese uitgebreidheid van die kerk, oor nasionale grense heen. 
G. C. Berkouwer handel in sy Dogmatiese Studiën in die eerste deel oor die kerk ook oor die begrippe katoliek en ekumenies ( $p$. 130 e.v.). Hy wys daarop dat die oorspronklike woord Katholikos algemeen beteken. In die begrip katoliek is altyd 'n sekere wydheid en ruimte beslote (aldus Berkouwer) - wydheid teenoor begrensing en isolering in tyd en ruimte. Dit open 'n universele perspektief i.v.m. die eskatologiese uitdrukking van die heil. Hy signaleer die gevaar dat meer gelet kan word op die breedte as op die diepte, die kwantitatiewe katolisiteit. Hy verklaar dat oikumene 'n duidelike „geografiese" betekenis het; dit het die wêreld in sy uitgebreidheid op die oog. Die uitgebreidheid moet ook met diepte gepaard gaan. Dit het te doen met die beslissende betekenis van die evangelieverkondiging in die hele wêreld. Vanuit die diepte kom dan die breedte in sig, net soos by die katolisiteit. Daarom kom hier die sendingroeping so pertinent binne die gesigsveld.

Ekumenies en katoliek is sinoniem wanneer ons let op die aspek van geografiese uitgebreidheid, die wêreldwye karakter van die kerk. Die begrip ekumenies sien egter ook op die hele kerk oor die hele wêreld. So kom die eenheid van die kerk binne die gesigsveld. Ekumenisiteit het o.i. nie slegs met geografiese uitgebreidheid te doen nie, maar ook met die eenheid en sy verbreking en herstel. Daarom handel ons in hierdie voordrag i.v.m. ekumenisiteit oor geskeidenheid en verskeidenheid.

Die katolisiteit van die kerk druk uit dat die gelowiges één Hoof besit en saam één liggaam vorm, sodat daar slegs één kerk is (éen liggaam) wat oor die hele wêreld versprei is. Die liggaam van Christus is katoliek. Ignatius het die kerk reeds katoliek genoem omdat dit oor die ganse aarde, in alle tye en plekke, alle gelowiges omvat en daar buite die kerk geen saligheid is nie. Die misvatting het daarin bestaan dat die kerk teenoor die kettery nie meer geestelik opgevat is nie, maar dat dit te veel veruitwendig en in 'n sigbare instituut beliggaam is.

Ondertussen handhaaf ons - en dit is die punt wat ons onderskrywe - dat die kerk wel deeglik ekumenies - institutêr tot openbaring moet kom, maar dan as pilaar en vastigheid (grondslag) van die waarheid ( 1 Tim. $3: 15$ ), getuigend en dienend op die wêreld gerig.

Natuurlik vind die ecclesia universalis ook vergestalting in die plaaslike kerk. Die water in 'n dam is nie kwantitatief nie, maar tog wel kwalitatief dieselfde water as in die groot oseaan.

\section{Riglyne uit die Heilige Skrif}

Die kerk word vergader uit elke stam en tong en nasie. Efes. 2 : 14; Rom. $10: 10-12$; Openb. $7: 9$. Van die begin van die werreld tot aan die voleinding vergader Christus sy kerk. Die volke word salig in hul uitverkorenes. Die boom van die mensheid word gered. Los takke word afgesny - dit is diegene wat verlore gaan. Christus is die tweede Verbondshoof (Rom. 5; 1 Kor. 15 ens.). Daar is 'n nuwe mensheid in Christus (Efes. 1, 2, ens.). Hy is die Hoof van die ecclesia universalis. Rom. $10: 12,13$; Gal. 3 : 28; Efes. 1 : 10; Kol. 1 : 19, 20. In Hom is die kerk universeel. In die begin staan die menslike geslag 
reeds as eenheid in sy organiese samehang voor ons. In Gen. $3: 15$ word van die ,saad" van die vrou gespreek. Die saad behels immers in die lewenskiem die samevatting van die hele plant. Die genade heg hom dus van die begin af aan die mensheid in sy geheel; dus nie net aan een volk of geslag nie, maar sy uitgangspunt is in die nog nie ontplooide mensheid. Dit gaan dus nie slegs om die redding van enkelinge nie, maar om die behoud van die mensheid; dit is 'n universele trek wat reeds heenwys na die katolieke karakter van die kerk (die herbore mensheid).

Met die roeping van Abraham word die bedding versmal, maar die uitsig bly helder aangesien in Abraham al die geslagte van die aarde geseën sal word (Gen. $12: 3$; Gal. $3: 8$ ). Abraham is die vader van 'n menigte van nasies (Gen. $17: 5$ ). Die belofte aan Abraham is nie alleen vir alle ,geslagte" nie (Gen. 12:3), maar ook vir alle „nasies" (Gen. $22: 18$ ). Hier is dit tewens duidelik dat alle nasies in die verbond met Abraham begrepe is, en dat die betrekking van Christus tot die nasies 'n verbondsbetrekking is. Israel is partikularisties met die lig van die besondere openbaring beweldadig; hy is draer van die belofte van die eeue, sodat straks vanuit hierdie middelpunt die boodskap van saligheid en verlossing hom oor die ganse menslike geslag mag verbrei. Daar was steeds wysende vingers na die bedeling wanneer die partikularisme deurbreek sou wees. Vgl. die volkeretafel in Gen. 10 (die mensheid is een groot familie; daar is verskeidenheid in die eenheid); verder let ons op die voorskrif dat nie net die eie seuns nie, maar ook die ingeborenes van die huis besny moes word, op die instelling van die proselitisme, die geskiedenis van Ragab, Rut en so meer. Daar was steeds oop vensters na die volkere om Israel heen. Vgl. Pss. $66: 4 ; 72 ; 87 ;$ Jes. $2: 2 ; 45: 22,23$; Jer. $3: 17$; Mal. $1: 11$ ens. In die volheid van die tyd verskyn Jesus Christus in die vlees as Seun van die mens. Hy is Wêreldredder. Vgl. o.a. Matt. $8: 11,12$. Aan die kruis staan die opskrif in Griekse, Romeinse en Hebreeuse letters (Luk. $23: 38$ ). In sy middelaarsdood lê Hy beslag op die volkere. Baie belangrik is Christus se koninklike proklamasie van anderkant die dood en anderkant die graf: Matt. $28: 19,20$. Daar moet dissipels gemaak word van ,al die nasies”. Natuurlike verwantskappe (familie, ras en volk) verloor nie hul betekenis vir die Nuwe Testament nie. Al het die volksgedagte van Israel oorgegaan op die kerk as die volk van God, die betekenis daarvan dat God 'n volk uitgekies het onder volkere om draer van die besondere openbaring te wees moet nie onderskat word nie. Daar sit 'n gedagte in wat deurloop: in die doopbevel (Matt. $28: 19$ ) gaan dit nie om geĩsoleerde individue nie, maar om nasies. Dit sluit direk aan by die belofte aan Abraham (Gen. $12: 3 ; 22: 18$ ). Verder staan dit in verband met die verbreiding van die evangelie. Dit gaan van volk tot volk, ,van Jerusalem af en verder" (Luk. 24: 47; vgl. Hand. $1: 8$ ). Die verbreiding van die evangelie veronderstel die bestaan van nasies, so kom daar gekerstende nasies naas heidense, en kan vermenging van gekerstende en heidense nasies ' $n$ bedreiging inhou vir die Christendom. Daar is ' $n$ innerlike, organiese verband tussen kërk en volk: in die kerk bestaan die volk voort. Die ongelowiges is die bome wat uitgekap 


\section{In die Skriflig}

word (Matt. $3: 10$ ). In sy gelowiges is die volk behoue. Dit word nader in Rom. 9-11 uitgewerk. Hierin is die volk Israel 'n voorbeeld vir elke volk (vgl. 1 Kor. $10: 11$; Thess. $2: 14$ ). Die menslike geslag word volksgewys gered, maar dan in sy uitverkorenes (vgl. Luk. $2: 14$ en Dan. $12: 1 b, 2)$. Dit is ter sake om 'n vers uit Totius se beryming van Openb. 5 : $9-14$ te siteer:

U't van die hemelhoog op aarde neer wou daal, en ons vir God gekoop uit alle volk en taal.

Die losprys was $u$ bloed wat $U$ vir ons gestort het, waardeur ons, rein gewas, 'n priestervolk geword het en konings in die ryk van onverstoorb're vrede, om God te dien en eer in eind'lose ewighede.

Op Pinksterdag, die groot oesdag, vyftig dae na die Paasfees, is die Gees van die verheerlikte Christus op alle vlees uitgestort. Die ware eenheid in die Heilige Gees kom tot Openbaring in die ontvangs van dieselfde Evangelie in die eie taal as lede van afsonderlike volke. Die eenheid is nie eendersheid nie. Daar is differensiasie. Die verskeidenheid van nasies (rasse) word ook daarin veronderstel en gehandhaaf dat die evangelie gehoor en bely word in die moedertaal (Hand. $2: 8,11$; Rom. $10: 9,10$ ). So alleen word die hart bereik en die wysheid van God in sy menigvuldigheid deur die mond bely. Die Evangelie word deur die kerk kragtens die sendingopdrag in Matt. 28 : 19 oorgedra van die een volk na 'n ander in sy taal - dit beteken oorbrugging van grense sonder uitwissing daarvan. Dit is nie 'n verskeidenheid tén die eenheid nie, maar in die eenheid. Dit is ook nie 'n eenheid téen die verskeidenheid nie, maar in die verskeidenheid. Natuurlike gemeenskappe en samehange van die menslike geslag word nie deur die geestelike gemeenskap in Christus opgehef nie, maar met mekaar versoen deur verwydering van vervreemding en vyandskap wat verskeidenheid tot geskeidenheid gemaak het. In 'n saamgeslote harmonie word die mensheid geheilig tot samewerking tot die hoogste doel, wat bestaan in die verheerliking van God. Terwyl dit kenmerkend is van die werke van God in die skepping en die herskepping dat die eenheid en verskeidenheid steeds bewaar bly, is die kenmerkende van Babel die verabsolutering van die besondere (volk of ras) en die vernietigende oplossing van die verskeidenheid in 'n gedwonge wêreldomvattende eenheid en enersheid.

Volgens die Heilige Skrif is die kerk universeel, met 'n wêreldroeping. Dit wil nie sê dat alle mense hoof vir hoof gered word nie - die begrensing is die uitverkiesing, maar dit is universeel in die sin dat elkeen wat in Christus glo, of hy Jood of heiden is, gered sal word. Dit is 'n katolieke Here, 'n katolieke Heilige Gees wat in die uitverkorenes onder alle nasies woon, 'n katolieke Evangelie (Matt. 28 : 19: al die nasies moet geleer word), 'n katolieke doop, 'n katolieke roeping om heilig te wees, 'n katolieke gebed om die koms van sy koninkryk, en so meer. In hierdie sin ken die Christendom geen grense van geslag of leeftyd, van stand of raad, van nasionaliteit of taal nie. Die Heilige Skrif open die eskatologiese 
perspektief dat die heerlikheid en eer van die nasies in die nuwe Jerusalem gebring sal word (Openb. $21: 26$ ).

\section{I.v.m. die ekumeniese roeping van die kerk moet ons onder- skei tussen geskeidenheid en verskeidenheid}

\section{A. Geskeidenheid}

Waar 'n pluraliteit van kerke met dieselfde belydenis binne dieselfde volksverband bestaan, is dit sondige geskeidenheid, 'n toestand van verskeurdheid waarin nie berus mag word nie. Onder die Reformatore het o.a. Bullinger en Melanchton die standpunt ingeneem dat die veelheid van kerke as 'n feit aanvaar moet word om dan daarby te berus. Dit lê in die lyn van die pluriformiteitsleer waarvolgens die pluraliteit van kerke as beginsel aanvaar word. Die uiterlike eenheid van kerke word dan gesoek in die weg van 'n oorkoepeling waarby die verskille verkleineer word tot verskeidenhede (nuanseringe, aksente ens.). Dit hou in 'n bestendiging van die verskille. Veelal is dit die kenmerk van die huidige ekumeniese bewegings. Die universele kerk is volgens hierdie standpunt in vele kerke verdeeld. wo. Protestantse, Oosters-Ortodokse, Rooms-Katolieke en ander kerke. Geeneen van hulle is met uitsluiting van die ander die heilige katolieke kerk nie. Die hereniging van die Christendom kan nooit bereik word deurdat 'n deel van die heilige katolieke kerk daarop staan dat ander dele hulle Christelike oortuiging sal verloën en hulle bydrae ter syde sal stel om terug te keer tot 'n deel van die universele kerk nie.

Hierteenoor stel ons ons eie standpunt wat daarop neerkom dat die veelheid van kerke aanvaar word, maar nie om daarby te berus nie. Calvyn het onverswak vasgehou aan die ecclesia universalis visibilis. Hieruit is die gedagte van 'n Ekumeniese Konvent gebore, bekend uit die korrespondensie met Cranmer (1556), nie om die verskille te oorkoepel of 'n eenheidskultus op te rig oor die kerke heen nie, maar om die eenheid te soek en te vind. Die pluraliteit is nie maar 'n verskeidenheid nie, maar 'n sondige geskeidenheid wat nie mag wees nie. Die verskillende kerke moet nie gesien word as aanvullende dele van een geheel nie, maar as stukke van 'n geskeurde geheel (vgl. Institusie van Calvyn, IV, 1, 2). Nie dat die liggaam van Christus geskeur is nie. Die eenheid van die kerk as mistieke liggaam van Christus is 'n werklikheid, maar die eenheid van die uitwendige kerk is 'n goddelike eis en opdrag. Hieruit vloei die roeping van die kerk voort om dit wat uitmekaar hou, broederlik met mekaar onder oë te sien om sodoende te bring in een kerkverband. $\mathrm{H}$. Bavinck sê uitdruklik dat daar in die hemel vir sodanige geskeidenheid geen plek sal wees nie (Geref. Dogmatiek IV, 303). Die kerke moet met mekaar die weg van Matth. 18 bewandel. Saam moet geworstel word om die waarheid beter te deurgrond, sodat ons mekaar daar in Christus kan vind. Soos by die heiligheid van die kerk moet die belydenis ook in die geval van die eenheid as ' $n$ roeping gesien word. Soos daar enersyds sprake is van liefde tot die waarheid $(2$ Thess. $2: 10$ ) en liefde wat hom in die waarheid verbly (1 Kor. $13: 6$ ), moet andersyds die waarheid ook in liefde betrag 
word (Efes. $4: 15$ ). Die indikatief - die vanselfsprekendheid waarmee die Nuwe Testament praat van die eenheid in Christus, roep as vanself die imperatief, die bevel tot herstel en bewaring van die eenheid op. Let daarop hoe sterk Paulus hom in 1 Kor. 1 : 13 uitlaat teen sondige partyskappe. Inderdaad, Christus is nie verdeel nie.

Die herstel van die eenheid in leer, diens en tug is opdrag, dit is 'n roeping met ekumeniese implikasies. Ons noem een deurslaggewende oorweging. As die drie Afrikaanse kerke op die sendingakker tree, moet dit noodwendig die heidene verwar as die geskeurdheid van die liggaam van Christus in ons eie geledere ook daar oorgeplant word.

Hierdie drie kerke het drie fases met mekaar deurloop te wete die swartsmeerfase, die oorkoepelingsfase nadat ons baklei het soos duiwels want ons is mos "susters"; nou is ons in die gespreksfase wat hopelik al meer goeie vrugte sal afwerp.

In verband met die geskeidenheid van kerke kan aanvaar word dat elke kerk wat betrokke is nie noodwendig die skuld, of al die skuld van die kerkskeuring dra nie. Die eenheid met die Here van die kerk kan onder bepaalde omstandighede die verbreking van 'n valse institutêre eenheid 'n eis maak, soos in die tyd van die Reformasie inderdaad gebeur het. Die Skrif weet egter ook van mense wat die kerk verlaat het en nooit deel daarvan was nie (vgl. bv. 1 Joh. 2 : 19); daar is in die kerk ook wolwe in skaapsklere (Matt. $7: 15$ ) en valse broeders (vgl. bv. 2 Kor. $11: 26$ ). Dit kan onder bepaalde omstandighede roeping wees om jou te onttrek aan die gemeenskap met valse broeders (2 Kor. $6: 14-18$; Gal. $1: 6-9$; 1 Tim. $6: 3-9$; Titus $3: 10,11 ; 1$ Joh. $4: 1-3 ; 2$ Joh. 9-11. Vgl. N.G.B., art. 28, „En om dit des te beter te kan onderhou, is dit die amp van alle gelowiges, volgens die Woord van God, om hulle af te skei van diegene wat nie tot die kerk behoort nie, en hulle te voeg by hierdie vergadering, op watter plek God dit ook al gevestig het, al sou ook die owerhede en verordeninge van soewereine vorste daarteen wees en al sou hulle die dood of enige lyfstraf moet ondergaan").

In hierdie verband sou ons ook kon verwys na wat Calvyn na vore bring oor articuli non fundamentales en articuli fundamentales.

Die erns van die implikasies van die verbreking van die eenheid en ekumenisiteit kan nie oordryf word nie; daarom is die roeping tot die herstel van hierdie verbrokenheid eweneens ' $n$ saak van die hoogste erms. Dit is niks minder as die bestaansgrond van die kerk wat hier in die gedrang kom nie, naamlik die band met die een Here. Die geloofwaardigheid van die Evangelie van Christus wat die kerk aan die wêreld moet verkondig kom in gedrang (Joh. $17: 21$ ). Hiermee word ook in die praktyk verloën wat in die negende artikel van die Apostolicum bely word.

Die akte van afskeiding in 1859 sluit af met die gebed van ons gereformeerde vaders dat by alle onderlinge verskil die broederliefde tussen die gemeentes mag bly en dat God mag gee dat ons weer met mekaar een sal word in leer, diens en tug. Langs die weg van biddende reformasie o.g.v. die Woord van God na binne en deur amptelike broederlike samespreking met mekaar moet die een- 
heid gesoek word. Gehoorsaamheid aan Christus kom tot openbaring in die gehoorsaamheid aan sy Woord, soos in belydenis en kerkregering weerspieël; daarom impliseer afdwaling van Christus en sy Woord altyd verbreking van die eenheid van die kerk. By herstel gaan dit dus om terugkeer tot die waarheid.

Kerke wat die fundamente van die waarheid handhaaf, maar in hulle seremonies verskil, is deur Calvyn as deel van die universele kerk beskou en erken. Hierdie erkenning was die spoorslag om te ywer vir 'n nouer vereniging in kerkverband. Ook teenoor die valse kerk bestaan daar volgens die Reformatore nog 'n roeping, naamlik om dit terug te roep na die Woord van God. By die interkerklike gesprek moet almal hulle onder die tug van God se Woord stel.

Feit is dat die ekumeniese roeping duidelik inhou dat die eenheid van die liggaam van Christus ook sigbaar, institutêr tot openbaring moet kom deur uitsuiwering van wat 'n sondige geskeidenheid veroorsaak het. Ons lê die klem op die saamkom in een kerkverband. Die eenheid van die kerk is nie slegs 'n geloofswerklikheid wat by die kerk na sy onsigbare sy mag bly steek nie. Die instituut is ingestel, dit is verordineer. Hierdie inrigting of vorm vind ons reeds in die Ou Testament. Die kerk tree op in bepaalde vorme. Daar is ampte en ampsdraers, daar is samekomste van die gemeente ens. Hierdie organisasie sit hom in die nuwe bedeling voort. Christus gee aan die kerk 'n welomskrewe inrigting. Hy stel die apostolaat in, onderskeie van die taak van die ander dissipels (Luk. $6: 13-16$ ). In Jerusalem vind ons 'n gemeente met 'n suiwere en deugdelike kerkinrigting (Hand. 2). Al spoedig word die diakonaat ingestel (Hand. 6) en later word ook ouderlinge of opsieners aangewys (Hand. $20: 28$; 1 Tim. $3: 2$ ). Onder die ouderlinge (presbuteroi) was daar spoedig ook enkeles wat met 'n besondere opdrag beklee is (Rom. $12: 8$; 1 en 2 Tim.; Titus $1: 5$; 1 Petr. $5: 1,2$ ), waaruit voldoende blyk dat die kerk 'n eie inrigting is. Dit is ook duidelik uit die sinode wat in Jerusalem gehou is (Hand. 15), en uit die feit dat die apostels spreek van verskillende kerke. Die instituut is inherent aan die kerk, dit is van die aanvang af met die lewe van Christus se kerk ten nouste verbonde. In Art. 28 N.G.B. bely ons dat ons verplig is om ons by hierdie heilige vergadering ,aan te sluit". 'n Mens kan nie by 'n abstrakte, onsigbare entiteit ,aansluit" nie. Dit ter stawing van ons standpunt dat die eenheid van die kerk tot sigbare, institutêre vergestalting moet kom.

\section{B. Verskeidenheid}

God het uit een bloed al die nasies van die mensheid gemaak (Hand. 17 : 26). Wat God saamgevoeg het, mag die mens nie skei nie. Alle mense stam van een mensepaar af. Behalwe die eenheid toon die skepping van God ook 'n ryke variasie en differensiasie. Wat God geskei het, mag die mens nie saamvoeg nie. Dit is 'n verskeidenheid binne die organiese eenheid, die een bloedgemeenskap in Adam. God self bewerk die verdeling van die mensheid in verskeidenheid, d.w.s. in rasse, kultuurkringe, volke e.d.m. deur sy oorspronklike 
kultuuropdrag en die Babelse verwarring en die verdere historiese verloop, en bepaal vir alle nasies hulle roeping, tye en woonplekke tot aan die voleinding. Hierdie verskeidenheid word alleen as gevolg van die sonde 'n verbrokenheid; die harmonie 'n disharmonie, die liefde word vervang deur vyandskap.

Teenoor die twee pole van 'n Nasionaal-Christelike en daarteenoor 'n kosmopolities saamgestelde kerk handhaaf ons dat die Christelik-Nasionale die Skriftuurlik verantwoorde uitgangspunt is. Daar is diegene wat die kerk nasionaal wil begrens en nie besef dat die kerk die nasionale grense moet transendeer nie. Die nasionale word dan oorbeklemtoon. Dit kan in sy konsekwensie ruik na die „reine Ras"-ideologie en die kerk laat beland onder die atoomafval van die Hitlerontploffing. Die Heilige Skrif ken nie volskerke nie, maar 'n volkerekerk. Dit bring geensins mee dat die identiteit van die volk opgehef word nie. Natuur en genade mag nie geskei word nie. Die kerk is nie beperk tot tye of plekke, rasse of kulture nie. Die kerk word uit die ganse menslike geslag vergader $(\mathrm{H}$. Kateg. vr. 54; Art. 27, N.G.B.), uit alle stamme, tale, volke en nasies (Openb. $5: 9$; Ps. 87; Jes. $2: 2,3 ; 19: 21-25$ ens.). Dit gaan nie bloot om die redding van die individu nie, maar om die volk Israel en om die nasies (alle nasies) wat in hulle uitverkorenes gered word (Gen. 22 : 18; Jes. 66 : 12; Dan. 12 : 1; Luk. 24 : 46; Rom. 9-11; Openb. $21: 24,26$ ). Die gemeenskap van die gelowiges is in sy diepste wese een en wêreldwyd. So word die verbrokkelde mensheid tot sy oorspronklike eenheid teruggevoer. Die uiteengeslane bestanddele van die menslike geslag word onder Christus weer tot 'n eenheid saam vergader.

Na sy wese is die kerk wêreldkerk. Dit is gerig op die behoud van die wêreld (oikoumene) deur die verkondiging van die evangelie (Matt. $28: 19$ ). Christus is Wêreldredder (Joh. $3: 16$ ), soos deur Hom as Skeppingsmiddelaar die wêreld tot stand gekom het (Joh. $1: 3$; Kol. $1: 16$ ). Die wêreld word in Christus gerekapituleer (anakephalaioo) - Efes. 1 : 10. So word Hy Hoof van alle dinge (vs. 22 ; Kol. 1 : 18-20), en insonderheid van sy liggaam, die kerk (Efes. $1: 22,23 ; 4: 15,16$ ).

Die universalisme van die Christendom het veelal in die slag gebly omdat die Christendom eintlik as Europese (witmans-)godsdiens beskou word. Die kerk moet hom onder die nasies in 'n pluriforme gestalte openbaar, met 'n eie karakter, 'n eie vorm en uitdrukking. A. Kuyper wys daarop dat ,bij behoud der beginselen en de daaruit getrokken hoofdlijnen, rijkdom van schakering naar tijd, toestand, volkskarakter, enz." gewens is. Die Sinode van die Geref. Kerk, Middelburg, Nederland, 1896, verklaar: „Nimmer mag de eisch gesteld worden dat de Javaan onze vormen overneme, maar moet uit den boezem zelf van het bekeerde deel der Javanen, die Oostersche vorm voor lied, gebed en belijdenis opkomen die bij zijn geaardheid past". In die verbondenheid moet daar dus tegelykertyd afsonderlikheid wees.

Die kerk moet, soos ons i.v.m. die geskiedenis reeds betoog het, ekumenies-instituter tot openbaring kom. Daar mag nie uit die sigbare na die onsigbare kerk uitgewyk word nie. Dit is éen kerk 
met sy sigbare en onsigbare kant. Hierdie eenheid van die liggaam van Christus moet in een kerkverband tot uitdrukking kom. Dit is 'n aantasting van die ekumeniese karakter van die kerk as die kerk in gebreke bly om oor die nasionale grense heen tot 'n sigbare, organisatoriese uitdrukking te kom van die een algemene kerk van die Skrif. Van die onsigbare kant besien, is die eenheid van die kerk as liggaam van Christus 'n onaantasbare werklikheid; van die sigbare kant besien, is dit 'n roeping - iets wat in die wêreld verwesenlik moet word.

Die verskillende taal- en volksgroepe moet plaaslik hul eie kerke institueer asook hul eie kerkverband tot op die nasionale vlak. Aparte instituering is nie alleen wenslik nie, maar ook noodsaaklik ter bevordering van die saak van Christus. Dit dien o.a. tot stimulering van die jonger kerke en tot verryking van die kerklike lewe. Die ekumeniese verband is ewe noodsaaklik om die geestelike eenheid tot openbaring te bring. Hieruit volg dat ras- en volksvermenging as beginsel en reël op kerklike gebied verwerp moet word. Dit is nie vir die kerk tot voordeel nie. Dit het die Here behaag dat op die Pinksterdag elkeen gehoor het dat in sy eie taal oor die groot dade van God gespreek word (Hand. $2: 11$ ). Die nagmaal as sakrament is 'n saak van die plaaslike kerk, waar die kerkraad toesig hou oor die toegang daartoe. Die nagmaal mag dus nie misbruik word as 'n demonstrasie van ekumeniese eenheid nie.

Ons voeg ten slotte die volgende stellinge by:

(a) Ekumenies is, soos aangetoon, vir 'n groot deel ook 'n geografiese (ruimtelike) begrip. Eenheid is 'n numeriese begrip. Die een hou implikasies vir die ander in. 'n Mens kan eenheid nastrewe (heelmaking van 'n stukkende kerk), sonder ekumenies werksaam te wees, d.w.s. die wêreld binne die gesigsveld te bring.

(b) Ons moet op die punt duidelik wees: Daar mag nie met die ekumeniese roeping versuim word totdat die eenheidstaak voltooi is nie. Die uitstryk van geskeidenheid is 'n groot roeping; daarby kom die roeping om ook die eenheid in die waarheid te vind en tot sigbare vergestalting te bring oor die nasionale grense heen.

(c) Die Wêreldraad van Kerke vermeng belydenisse en volke. Die G.E.S. moet waak dat hy nie dieselfde weg opgaan nie.

(d) Dit lê nie op die weg van die kerk om by 'n ekumeniese beweging aan te sluit nie. Die kerk is immers eiesoortig (sui generis), van ' $n$ ander aard as 'n gewone organisasie; dit is die corpus Christi (H. Kateg., Sondag 21; N.G.B., Art. 27-29). Omdat die kerk eiesoortig is, kan dit nie deel word van 'n organisasie met sy eie grondwet en reglement wat 'n ander karakter het en 'n eie stempel dra nie. Dit is in stryd met die presbiteriale stelsel van kerkregering. Aansluiting beteken tog vir die kerk niks anders nie as om in kerkverband te tree. Nóg die Konfessie nóg die Kerkorde ken enige aansluiting by iets anders as 'n kerk of 'n kerklike vergadering. Die Konfessie spreek van die kerk, en laat geen opening vir bewegings of ${ }^{*}$ organisasies wat op die terrein van die kerk beweeg of sekere funksies van die kerk 
wil oorneem nie. Die Kerkorde handel oor kerklike vergaderings as oor die enigste plek waar kerklike sake behandel kan word (vgl. Art. 30, Kerkorde).

Aan die ander kant behoort die kerk van sodanige ekumeniese organisasies deeglik kennis te neem en selfs 'n vorm van kontak te implementeer. Daar moet steeds 'n ekumeniese openheid aan die dag gelê word. Die kerk het ook 'n roeping teenoor kerke wat in rade saamkom en teenoor die rade wat die betrokke kerke saambind.

(e) Die amp van die gelowiges (die kerk is tog die mense wat daartoe behoort) moet ook in die vervulling van die ekumeniese roeping tot ontluiking kom. In die kerk as organisme moet die gemeenskap van die heiliges ook beoefen word. Daar moet van die eenvoudigste gelowiges 'n getuienis uitgaan, elkeen op sy pos en in sy kring, spontaan en vanselfsprekend. Namate daar groei in Christus is, $\mathrm{Hy}$ in ons gestalte $\mathrm{kry}$, sal ons ook ,op mekaar gaan lyk" en na mekaar toe groei, die groei na die volheid wat staan teenoor die parsiële, die verengde. Die katolisiteit kan nie van die belydenisvraag losgemaak word nie; die katolisiteit spreek juis kragtig mee in die dinamiese en totale lewe van die kerk op weg na die volheid.

(f) Die ekumeniese roeping vind sy begrensing en ganse gerigtheid daarin dat die kerk pilaar en grondslag (vastigheid) van die waarheid moet wees; d.w.s. dat die gesag van die Woord van God erken moet word. Daar mag nie saamgeflans word wat nie bymekaar hoort nie. Gemeenskap met God beteken eendragtige gehoorsaamheid aan die Woord van God en gemeenskaplike uitdrukking van die geloof, sowel in belydenis as in kerkregering volgens die Woord van God. Calvyn, Institusie IV, 11, 5 .

(g) Dit is 'n ernstige vraag of daar reg gehandel word deur die ekumeniese aktiwiteit streng tot die vlak van die Sinode te beperk, en dan veelal tot die opdrag aan enkele deputate. Het die plaaslike kerk nie ook 'n roeping in hierdie verband nie? Indien wel, wat behels dit en hoe moet dit nagekom word?

\section{VERNAAMSTE BRONNE:}

A. G. Honig: De kosmische betekenis van Christus.

J. H. Bavinck: Inleiding in de Zendingwetenschap.

Stephen Neill: A History of Christian Missions.

J. C. Coetzee: Volk en Godsvolk in die Nuwe Testament.

H. Berkhof: Gods éne kerk en onze vele kerken; De Katholiciteit der Kerk.

G. C. Berkouwer: De Kerk I (Dogm. Studiën).

P. J. Richel: Het kerkbegrip van Calvijn.

A. D. R. Polman: Christelijke Encyclopaedie, III, Sub voce Kerk.

H. Hoeksema: Reformed Dogmatics. ,

J. J. Knap: De Kerk.

H. Bavinck: Gereformeerde Dogmatiek; De Katholiciteit van Christendom en Kerk.

A. J. van Wyk e.a.: Die Ekumene. 
Nasionale Sinode, Geref. Kerk in S.A., Acta 1961 (rapport oor rasseverhoudinge); 1967 en 1970 (rapport, Deputate vir Ekumeniese Sake).

H. Kraemer: The Christian Message in a non-Christian World.

H. Kuyper: De Katholiciteit der Geref. Kerken.

W. G. de Vries: Calvijns oecumeniese betekenis.

W. Nijenhuis: Calvinus oecumenicus.

o. S. Tomkins: The wholeness of the church.

H. Söderblom: De ware broederskap.

B. Duvenage: Art. in Die Koninkryk van God: Koninkryk en ekumene.

(Voordrag by die Dogmatologiese Werkgemeenskap te Pretoria, Julie 1974). 